\title{
Delving into the Relationship between LOC, MI, and Reading Proficiency
}

\author{
Farrokhlagha Heidari \\ University of Sistan and Baluchestan, 0098-09153414937, Iran \\ Najme Khorasaniha \\ University of Sistan and Baluchestan, 0098-09173051270, Iran
}

\begin{abstract}
Locus of control (LOC) refers to individuals' perceptions about the underlying main causes of events in their lives. Multiple intelligences (MI), as another psychological concept, deals with the various aspects of intelligence each individual may possess. This paper reports the results of a study designed to examine any relationship between LOC and MI on the one hand, and any possible relationship between each of these two constructs and reading proficiency, as a language component, on the other. To this end, 59 EFL students from University of Sistan \& Baluchestan and Islamic Azad University of Zahedan answered a 28-item LOC questionnaire, a 90-item intelligence questionnaire, and a reading comprehension section of a TOFEL test. The results indicated no significant relationship between LOC and MI; however, a significant relationship was observed between MI and reading proficiency. Among the different domains of intelligence, the visual intelligence made the greatest contribution in predicting reading proficiency. The relationship between LOC and reading proficiency also was significant. In other words, a significant positive correlation was found between internal orientation and reading proficiency as well as visual intelligence and reading scores. It can be concluded that LOC and MI are significant variables regarding reading proficiency and should be highly considered while developing strategies for reading instruction
\end{abstract}

Index Terms-locus of control, multiple intelligences, reading proficiency

\section{INTRODUCTION}

Educators all over the world are in search of a teaching method or strategy that may increase learner achievement. Among the many factors that might have direct influence on language acquisition are learners' individual differences in terms of psychological variations. Based on Dörney (2005), the field of psychology has two objectives: to find out the general principles of human mind and to explore the uniqueness of the individual mind also called differential psychology or individual differences (IDs). IDs refer to characteristics unique to each individual. However, IDs are the "most consistent predictors of L2 reading success" (Dörney, 2005, p.2).

Recently much attention is given to such variations and many scholars (e.g. Culvar \& Morgan, 1977; Ghonsooly \& Elahi, 2010; Fatemi \& Elahi, 2010, to name a few) are seeking to find out whether there is any relationship between students' performance in a second language (L2) and individual variations. In other words, they are seeking to explore whether learner differences, mostly psychological, have anything to do with language proficiency. Among the most dominant psychological constructs that lead to IDs, one can name Locus of Control and Multiple Intelligences.

\section{A. Locus of Control (LOC)}

LOC refers to the expectancies about the causations of actions and outcomes (Rotter, 1966). Rotter proposed a model for LOC that suggested a bipolar dimension to express control from internal to external (cited in Matricardi, 2006). LOC is a "generalized expectancy reflecting the degree to which individuals perceive consequences as contingent on their own behavior and abilities (internal control) rather than on some external force such as luck, chance, fate, or powerful others (external control)" (Janssen \& Carton, 1999. p.1).

Previous studies indicated a significant positive relationship between internal orientation and high academic achievement. Findley \& Cooper (1983) reviewed 98 studies that investigated LOC and academic achievement. Seventy percent of the hypotheses reported internals to have significantly higher academic achievement than externals. They also found that males were more internal than females (cited in Goyal, 2000).

Such findings might be due to the fact that internalizers feel great pride when they perform an action successfully, and they expect to be rewarded. This feeling might bring about motivation that leads to frequent success. Externalizers, however, attribute their success to extraneous factors such as luck or fate. Therefore, they lack motivation as it is the case for internalizers. As their motivation decreases, they do not do their best to achieve extensive success.

Based on Cairn et al. (1990), LOC becomes more internal as individuals reach a certain age. They compared the result of LOC evaluation at two time intervals. The subjects, all 17 -years-old students, were found to become more internally oriented 18 month after the first measurement (as cited in Moore, 2006). 
Goyal (2000) examined the relationship between LOC and academic achievement. To do so, the scores obtained on Rotter's I-E scale were compared with different levels of academic achievement, based on class placement. The results proved a significant positive relationship between LOC and academic achievement. He also explored the relationship between gender and LOC. Based on Goyal, females proved to be slightly more internal than males. However, the correlation was not statistically significant.

Ghonsooly \& Elahi (2010) examined the relation between LOC and General English (GE) course achievement in an EFL context. The results revealed a positive relationship between the students' LOC and their GE achievement course. In other words, the internalizers proved to have higher GEs than the externalizers.

LOC proved to have a significant relationship to reading achievement. In one investigation done by Culvar \& Morgan (1977), a significant positive relationship was found between internal orientation and higher levels of reading achievement.

Fatemi and Elahi (2010) examined the relationship between LOC, L2 reading achievement, and use of language learning strategies in an EFL context. According to the findings, the EFL learners identified with internal LOC (internalizers) used metacognitive strategies more frequently than those with external LOC (externalizers). The L2 learners with higher LOC orientation also proved to be better readers.

\section{B. Multiple Intelligences}

Binet, a French psychologist, was the first one who tried to categorize students as those who would probably experience difficulty in school and those of talented and gifted category. He designed the first intelligence test that discriminated between students regardless of the fact that a single test may not capture all of an individual's abilities and potential. He ascertained questions that predicted success if answered correctly and those that "foretold school difficulties" if answered wrongly (Gardner, 1999b).

However, based on Hoerr (2000), a single test and a single score may not feasibly represent students' abilities and potential.

Gardner's proposal of the MI theory (1983) highly challenged this assumption about intelligence. Based on Gardner (1983) "intelligence is the ability to solve a problem or create a product that is valued in a culture" (cited in Hoerr, 2000)

Gardner (1983) believed that intelligence has to do with the capacity for problem-solving and fashioning products in a natural setting. Therefore, sitting students at their chairs, asking them to take an intelligence test, and deciding on the students' abilities on the basis of the scores does not seem logical.

Gardner proposed seven areas of intelligences in his Frames of Mind (1983). Since 1983, the MI theory seized the attention of dozens of scholars. Many educators, who felt a gap in the educational system of the time, welcomed Gardner's model of intelligence (e.g., Armstrong, 2009; Campbell and Campbell, 1999; Hoerr, 2000, to name a few). He enumerated these intelligences as verbal/linguistic, logical/mathematical, visual/spatial, bodily/kinesthetic, musical/rhythmic, and interpersonal/intrapersonal. He has more recently added naturalistic intelligence and has suggested that an existential intelligence might exist (Gardner, 1999b).

Armstrong (2009), for example, was among the scholars who quickly put Gardner's model into experience. Based on Armstrong, there were many disabled students who proved to be smart in one way or another (Armstrong, 2009, p.1). The problem, he stated, would have been with the testing occasion and classification process. The IQ tests were supposed to tackle a limited domain of intelligence, leaving the other intelligence profiles apart. Since 1983, a couple of studies have investigated MI theory in practice.

Campbell and Campbell (1999) published the improvement six schools gained using the theory of MI. In 1992, the students of Russell Elementary School in Lexington, Kentucky, scored in the 30th percentile. Over 50\% of the students ranked at the novice level. They applied MI in instruction and assessment, and by 1996, the students' scores doubled and no student ranked as novice.

Hoerr (2000) dealt with MI implementation at schools. He compared traditional intelligence models to the MI theory. He believed that MI can help discover the strengths and weaknesses of students. However, special concern is needed not to misapply MI. In other words, teachers must devote time and energy to digest MI principles and then decide how to use MI in curriculum development, instructional processes, and ultimate assessments.

Razmjoo (2008) investigated the relationship between MI and English language proficiency among the Iranian Ph.D. candidates who participated in Shiraz University Ph.D. Entrance Exam. The result showed no significant relationship between MI and English language proficiency in the Iranian context. However, he concluded that the results were local, not universal.

Hashemi (2008) investigated the relationship between MI and reading comprehension. The participants included 122 Iranian undergraduate EFL students who were asked to take part in an IELTS test and fill out McKenzie's MI questionnaire. The finding showed that kinesthetic and verbal intelligences made the greatest contribution toward predicting reading ability scores.

Ghazanfari (2009) evaluated the role of visualization in reading comprehension. He instructed a group of readers to visualize before reading, while reading and after reading. The result of the reading comprehension test, that was administered two weeks later, indicated that visualizers outperformed nonvisualizers who received no instruction. Therefore, visual intelligence acted as a predicting factor when it comes to reading comprehension ability. 
Tahriri \& Yamini (2010) investigated the effectiveness of the MI-inspired instruction in an EFL context. Two groups of subjects were chosen. The control group received verbal-linguistic instruction. For the experimental groups, some activities were refined and implemented to invoke various types of intelligence. The result showed the outperformance of the experimental group supporting the significance of the implementation of the MI-inspired instruction in an EFL context.

Pishghadam, Khodadady and Khoshsabk (2010) examined the effects of visual and verbal intelligence-based instruction on students' vocabulary retention and production. The subjects included 71 male and female students who were divided into visual experimental, verbal experimental, and control groups. Thirty five words were instructed to these three groups via various procedures: The verbal experimental group received the words verbally. The visual experimental group received them visually while the control group was instructed traditionally. Based on the findings, the visual experimental group outperformed the other two groups.

Although many scholars are going ahead with MI theory, Gardner himself believes that his theory lacks experimental research: "While MI theory is consistent with much empirical evidence, it has not been subjected to strong experimental test" (Gardner, 1993, p. 33).

There are a couple of studies investigating the relationship between either MI or LOC and some other factors (Findley \& Cooper, 1983; Ghonsooly \& Elahi, 2010; Fatemi and Elahi, 2010; Razmjoo, 2008; Hashemi, 2008). To the best of the researchers' knowledge, no comparative study in Iran has concentrated on the relationship between MI and LOC in an EFL context. Therefore, the gap felt by the scholars with ample experimental evidence on MIT on the one hand (Gardner, 1993), and lack of experimental research concerning the relationship between MI and LOC on the other, urged the researchers to conduct such an study in order to evaluate the otential relationship between these two psychological constructs and the influence they may have on reading proficiency as an inseperable skill from the phenomenon of language.

\section{Rerearch Questions}

Within the scope of this study, the following questions were concerned:

Q1. Is there any significant relationship between LOC and MI?

Q2. Is there any significant relationship between LOC and L2 reading proficiency?

Q3. Is there any significant relationship between MI and L2 reading proficiency?

\section{METHODOLOGY}

\section{A. Participants}

The sample consisted of 59 male and female senior students majoring in English Literature, TEFL, and English Translation at University of Sistan \& Baluchestan and Islamic Azad University of Zahedan. The reason for selecting such a sample was that all subjects were studying English in an EFL context. It should be mentioned that the participants were not randomly selected; in fact, all the seniors studying at these two universities were included in the study.

\section{B. Instruments}

The instruments were as follows: An MI questionnaire, the Internal Control Index (ICI), and a TOEFL reading test.

1. MI Questionnaire

The participants were given an MI questionnaire including 90 items measuring the nine types of intelligences. The validity of the questionnaire was confirmed by eight experienced assistant professors in the department of foreign languages and linguistics at Shiraz University. The internal consistency of the questionnaire turned out to be 0.89 , using Cronbach's alpha.

2. Internal Control Index

For the purpose of this study, the Internal Control Index (Duttweiler, 1984) was used to measure the participants' LOC. This scale contained 28 five-point Likert-type items that produce a possible range of scores from 28 to 140 with higher scores reflecting higher internal LOC and lower scores reflecting higher external LOC. For the sake of clarity and simplicity, the scale was translated into Persian by Ghonsooly and Elahi (2010). They Used Cronbach's alpha to check the reliability of the translated version which resulted in a coefficient of 0.82 .

3. TOEFL Reading Test

The participants were also given four reading passages from Longman-IBT Preparation Course TOEFL Test (2006). The passages were taken from four Mini Test sections that contained tests for all the other skills as well. The reliability of the test was determined using Cronbach's alpha, and it turned out to be .83, which is an acceptable and high index of reliability. The overall number of questions was 49 with a time allotment of 55 minutes.

\section{Data Collection Procedure}

First of all, the participants were informed orally about the objectives and procedures of the reading test. They were also assured that the results woud be kept confidential. Then, a reading section of a TOFEL Test, consisting of four passages and 49 questions were administered on all participants in order to evaluate their reading proficiency. 
During the second session, the 90-item MI questionnaire that included nine sections was distributed among the participants. They had ample time to go through all the questions. During the same session, the ICI was distributed among the participants to measure their LOC. They answered the questions in about 20 minutes. The subjects were informed that their scores had nothing to do with their course grades to avoid any external pressure such as anxiety or test stress. Half of the items were worded so that the high internally oriented respondents were expected to answer half at the "usually" end of the scale and the other half at the "rarely" end of the scale. The "rarely" response was scored as five points on items $1,2,4,6,11,14,17,19,22,23,24,26$, and 27; for the rest of the items, the response "usually" was scored as five points.

\section{RESULTS}

Table 1shows the descriptive analysis of the participants' LOC:

TABLE 1.

BASIC DESCRIPTIVE STATISTICS FOR THE LOC

\begin{tabular}{|l|l|l|l|l|l|}
\hline FACTOR & $N$ & Minimum & Maximum & Mean & Std. Deviation \\
\hline LOC & 59 & 62.00 & 126.00 & 96.37 & 12.6 \\
& & & & & \\
\hline
\end{tabular}

To answer the first question of the study concerning the relationship between MI and LOC, correlations were run:

TABLE 2.

CORRELATIONS FOR TYPES OF INTELLIGENCES AND LOC

\begin{tabular}{|c|c|c|c|c|c|c|c|c|c|c|}
\hline Variables & Logical & Visual & Musical & Bodily & $\begin{array}{l}\text { Inter- } \\
\text { personal }\end{array}$ & $\begin{array}{l}\text { Intra- } \\
\text { personal }\end{array}$ & Naturalistic & Existential & Linguistic & Loc \\
\hline Logical & 1 & $.498^{* *}$ & .19 & $.29^{*}$ & $.33^{* *}$ & .25 & $.28^{*}$ & $.40^{* *}$ & $.46^{* *}$ & -.19 \\
\hline Visual & $.49^{* *}$ & 1 & $.30^{*}$ & $.37^{* *}$ & $.31^{*}$ & $.31^{*}$ & $.40^{* *}$ & $.38^{* *}$ & $.42^{* *}$ & -.08 \\
\hline Musical & .19 & $.305^{*}$ & 1 & $.40^{* * *}$ & $.59^{* * *}$ & $.51^{* *}$ & .25 & $.31^{*}$ & $.42^{* *}$ & -.09 \\
\hline Bodily & $29^{*}$ & $.377^{* *}$ & $.40^{* *}$ & 1 & $.58^{* *}$ & $.52^{* *}$ & $.31^{*}$ & $.37^{* *}$ & $.54^{* *}$ & -.08 \\
\hline Inter-personal & $.33^{* *}$ & $.310^{*}$ & $.59^{* *}$ & $.58^{* *}$ & 1 & $.45^{* *}$ & .23 & $.39^{* *}$ & $.45^{* *}$ & -.07 \\
\hline Intra-personal & .25 & $.314^{*}$ & $.51^{* *}$ & $.52^{* *}$ & $.45^{* *}$ & 1 & .23 & $.48^{* *}$ & $.47^{* *}$ & .005 \\
\hline Naturalistic & $.28^{*}$ & $.403^{* *}$ & .25 & $.31^{*}$ & .23 & .23 & 1 & $.34^{* *}$ & $.45^{* *}$ & -.15 \\
\hline Existential & $.40^{* *}$ & $.386^{* *}$ & $.31^{*}$ & $.37^{* *}$ & $.39^{* *}$ & $.48^{* * *}$ & $.34^{* *}$ & 1 & $.41^{* *}$ & -.25 \\
\hline Linguistic & $.46^{* *}$ & $.428^{* *}$ & $.42^{* *}$ & $.54^{* *}$ & $.45^{* * *}$ & $.47^{* *}$ & $.45^{* *}$ & $.41^{* *}$ & 1 & -.21 \\
\hline Loc & -.19 & -.086 & -.09 & -.08 & -.07 & .005 & -.15 & -.25 & -.21 & 1 \\
\hline
\end{tabular}

Based on Table 2, as it is shown in the last column, no significant relationship was found between LOC and any of the intelligence types. To have a clearer picture of the data, multiple regressions were run:

TABLE 3.

MULTIPLE REGRESSIONS FOR TYPES OF INTELLIGENCES AND LOC

\begin{tabular}{|l|l|l|l|}
\hline Variables & Beta & $\mathbf{t}$ & Sig. \\
\hline Linguistic & .13 & .46 & .13 \\
\hline logical & .18 & .57 & .21 \\
\hline Visual & .12 & 2.43 & .21 \\
\hline Musical & .11 & 1.34 & .12 \\
\hline Bodily & .32 & 1.23 & .13 \\
\hline Interpersonal & .14 & 1.23 & .12 \\
\hline Intrapersonal & .12 & .46 & .23 \\
\hline Naturalistic & .14 & .87 & .12 \\
\hline Existential & .21 & 1.73 & .12 \\
\hline
\end{tabular}

The results of Table 3 show that the levels of significance for all intelligence types are greater than .05 ( $>$ >05), indicating that none of the nine intelligence profiles can act as a predictor of LOC.

With regard to the second question concerning the relationship between LOC and L2 reading proficiency, Pearson correlation formula was applied: 
TABLE 4.

THE RELATION BETWEEN LOC AND L2 READING PROFICIENCY

\begin{tabular}{|c|c|c|c|}
\hline & & Loc & Reading \\
\hline Loc & $\begin{array}{l}\text { Pearson Correlation } \\
\text { Sig. (2-tailed) } \\
\mathrm{N}\end{array}$ & $\begin{array}{l}1 \\
59\end{array}$ & $\begin{array}{l}.26^{*} \\
.020 \\
59\end{array}$ \\
\hline Reading & $\begin{array}{l}\text { Pearson Correlation } \\
\text { Sig. (2-tailed) } \\
\mathrm{N}\end{array}$ & $\begin{array}{l}.26^{*} \\
.020 \\
59\end{array}$ & $\begin{array}{l}1 \\
59\end{array}$ \\
\hline
\end{tabular}

Table 4 demonstrates that the correlation coefficient is significant at $p<.05$. Therefore, there is a significantly positive relationship between the two variables.

In order to see whether the difference between the internalizers and externalizers in terms of reading scores was significant, an independent t-test was run. First of all the descriptive analysis of the participants' reading scores is presented in table 5. The sample included 59 participants that were categorized as externalizers (31) and internalizers (28). It is worth mentioning that the median of the LOC scores was used to categorize the students as internalizers or externalizers. Therefore, students with scores above 93 were grouped as internalizers, and those with scores below 93 were considered as externalizers.

TABLE 5:

A COMPARISON OF EXTERNALIZERS' AND INTERNALIZERS' MEAN SCORES IN L2 READING PROFICIENCY

\begin{tabular}{|l|l|l|l|l|l|}
\hline L2 Reading & $\mathbf{N}$ & Mean & Std. Deviation & Std. Error Mean \\
\hline \multirow{2}{*}{ LOC } & Internal & 28 & 26.07 & 9.289 & 1.75 \\
\cline { 2 - 7 } & external & 31 & 20.67 & 5.99 & 1.07 \\
\hline
\end{tabular}

According to the above table, internalizers proved to have the mean score of 26.07 and standard deviation of 9.28 , while the mean reading score of the externalizers turned out to be 20.67 with the standard deviation of 5.99. Table 6 demonstrates whether this difference in mean scores was significant or not.

TABLE 6.

DETERMINING THE SIGNIFICANCE OF THE MEAN SCORES DIFFERENCE IN L2 READING PROFICIENCY

\begin{tabular}{|c|c|c|c|c|c|c|c|c|c|}
\hline \multirow{3}{*}{ L2 Reading } & \multicolumn{2}{|c|}{$\begin{array}{l}\text { Levene's Test for } \\
\text { Equality of Variances }\end{array}$} & & & & & & \multicolumn{2}{|c|}{ t-test for Equality of Means } \\
\hline & \multirow[t]{2}{*}{$\mathrm{F}$} & \multirow[t]{2}{*}{ Sig. } & \multirow[t]{2}{*}{$\mathrm{T}$} & \multirow[t]{2}{*}{ df } & \multirow[t]{2}{*}{ Sig. (2-tailed) } & \multirow{2}{*}{$\begin{array}{l}\text { Mean } \\
\text { Difference }\end{array}$} & \multirow{2}{*}{$\begin{array}{l}\text { Std. Error } \\
\text { Difference }\end{array}$} & \multicolumn{2}{|c|}{$\begin{array}{l}95 \% \text { Confidence Interval of } \\
\text { the Difference }\end{array}$} \\
\hline & & & & & & & & Lower & Upper \\
\hline $\begin{array}{l}\text { Equal variances } \\
\text { assumed }\end{array}$ & 10.36 & .002 & 2.67 & 57 & .010 & 5.39 & 2.01 & 1.35 & 9.43 \\
\hline $\begin{array}{l}\text { Equal variances not } \\
\text { assumed }\end{array}$ & & & 2.61 & 45.36 & .012 & 5.39 & 2.05 & 1.24 & 9.54 \\
\hline
\end{tabular}

The level of significance, as it is observable in table 6, turned out to be .012 that indicates a significant relationship between L2 reading proficiency and LOC. In other words, students with higher LOC orientation are better L2 readers.

The third question addresses the relationship between MI and L2 reading proficiency. The descriptive analysis of the participants' reading scores is presented in Table 7:

TABLE 7:

BASIC DESCRIPTIVE STATISTICS FOR THE READING SCORES

\begin{tabular}{|l|l|l|l|l|l|}
\hline FACTOR & N & Minimum & Maximum & Mean & Std. Deviation \\
\hline Reading & 59 & 4.00 & 42.00 & 23.23 & 8.13 \\
\hline
\end{tabular}

In order to find the relationship between MI and reading scores, correlations were used: 
TABLE 8:

CORRELATION FOR TYPES OF INTELLIGENCES AND READING

\begin{tabular}{|c|c|c|c|c|c|c|c|c|c|c|}
\hline Variables & Logical & Visual & Musical & Bodily & Inter-personal & Intra-personal & Naturalistic & Existential & Linguistic & Reading \\
\hline Logical & 1 & $.49^{* *}$ & .194 & $.29^{*}$ & $.33^{* *}$ & .25 & $.28^{*}$ & $.40^{* *}$ & $.46^{* *}$ & .08 \\
\hline Visual & $.49^{* *}$ & 1 & $.305^{*}$ & $.37^{* *}$ & $.31^{*}$ & $.31^{*}$ & $.40^{* *}$ & $.38^{* *}$ & $.42^{* *}$ & $.53^{* *}$ \\
\hline Musical & .19 & $.30^{*}$ & 1 & $.40^{* * *}$ & $.59^{* *}$ & $.51^{* *}$ & .25 & $.31^{*}$ & $.42^{* *}$ & .30 \\
\hline Bodily & $.29^{*}$ & $.37^{* *}$ & $.407^{* *}$ & 1 & $.58^{* *}$ & $.52^{* *}$ & $.31^{*}$ & $.37^{* *}$ & $.54^{* *}$ & .30 \\
\hline Inter-personal & $.33^{* *}$ & $.31^{*}$ & $.596^{* *}$ & $.58^{* *}$ & 1 & $.45^{* *}$ & .23 & $.39^{* *}$ & $.45^{* *}$ & .16 \\
\hline Intra-personal & .25 & $.31^{*}$ & $.519^{* *}$ & $.52^{* *}$ & $.45^{* *}$ & 1 & .23 & $.48^{* *}$ & $.47^{* *}$ & .28 \\
\hline Naturalistic & $.28^{*}$ & $.40^{* *}$ & .251 & $.31^{*}$ & .23 & .23 & 1 & $.34^{* *}$ & $.45^{* *}$ & .19 \\
\hline Existential & $.40^{* * *}$ & $.38^{* *}$ & $.310^{*}$ & $.37^{* *}$ & $.39^{* *}$ & $.48^{* *}$ & $.34^{* * *}$ & 1 & $.41^{* *}$ & .13 \\
\hline Linguistic & $.46^{* *}$ & $.42^{* *}$ & $.420^{\text {*** }}$ & $.54^{* *}$ & $.45^{* *}$ & $.47^{* *}$ & $.45^{* *}$ & $.41^{* *}$ & 1 & .17 \\
\hline Reading & .08 & $.53^{* *}$ & .301 & .30 & .16 & .28 & .19 & .13 & .17 & 1 \\
\hline
\end{tabular}

Based on the above table, the reading ability has high correlation with visual intelligence (i.e., .53 which is significant at $\mathrm{p}<0.01$ ) and low correlation with logical intelligence. Therefore, the only intelligence profile that highly correlates with reading proficiency was the visual one.

At this phase of the analysis, a multiple regression was run to observe which multiple intelligence subscales (as independent variables), if any, can predict the reading ability (as the dependent variable).

TABLE 9:

MULTIPLE REGRESSIONS FOR TYPES OF INTELLIGENCES AND READING PROFICIENCY

\begin{tabular}{|l|l|l|l|}
\hline Variables & Beta & t & Sig. \\
\hline Linguistic & .15 & .96 & .37 \\
\hline Logical & .08 & .58 & .14 \\
\hline Visual & .22 & 1.63 & $.004^{*}$ \\
\hline Musical & .21 & 1.44 & .13 \\
\hline Bodily & .26 & 1.73 & .21 \\
\hline Interpersonal & .17 & 1.05 & .12 \\
\hline Intrapersonal & .13 & .96 & .40 \\
\hline Naturalistic & .13 & .99 & .24 \\
\hline Existential & .17 & 1.21 & .12 \\
\hline
\end{tabular}

As the above table shows, the only intelligence that may act as the predictor of reading ability was visual intelligence with the significance level of .004, which is lower than .05 . Therefore, of the 9 intelligence profiles, visual intelligence was observed to make statistically significant contributions to this prediction.

\section{DISCUSSION}

The results of the data analysis with regard to the first research question revealed no significant relationship between intellectual preferences and LOC orientation. Although these two psychological constructs seem to be interrelated at the first glance, the findings proved no significant relationship between the two.

With regard to the second research question concerning the relationship between LOC and reading proficiency, the results showed a significant positive relationship between internal orientation and reading scores. In other words, the more internally oriented the participants, the better readers they are. The findings of the study are in agreement with those of the previous researchers mentioned in the literature section (Culver \& Morgan, 1977; Fatemi \& Elahi, 2010; Findley \& Cooper, 1983; Ghonsooly \& Elahi, 2010).

As it was cited in the preceding paragraph, studies have shown repeatedly that internalizers are better L2 achievers. This might be due to the fact that internalizers take control of their life events and feel responsible for what happens to them that might be a source of motivation to try hard and gain excessive success. An individual with an internal orientation who studies hard and does well on a test would attribute the success to his or her own endeavor and continue to do his/her best on the forthcoming situations. On the other hand, an individual with an external LOC may do well on a testing occasion but attribute the success to factors such as luck, chance, or an easy test. Therefore, the success would not act as a source of motivation for them as it is the case with the internalizers. Furthermore, individuals with an internal orientation follow different learning styles compared to externalizers.

Classroom teachers seem to have more difficulty dealing with externalizers as they do not consider any order for the world and rely mostly on powerful others rather than their own abilities (Rotter, 1966).

Teachers and instructors aim at modifying the curriculum and instructional procedure to meet students' needs and improve their proficiency levels. To this end, they must always consider factors that may have direct and indirect 
influence on students' achievement. As stated above, there are a number of researches, the results of which indicate a significant positive relationship between internal orientation and language achievement. Based on Lynch, Hurford, \& Cole (2002), LOC as a psychological construct predicts grades much better than standardized achievement test scores do.

With respect to the third research question concerning the relationship between MI and reading proficiency, a significant positive relationship was observed between reading scores and visual intelligence. The result of the present investigation is not exactly in the same line with those of other researchers. However, contradictory results are observed in the previous studies. McMahan, Rose \& Parks (2004) and Motalebzadeh \& Manouchehri (2009) concluded that logical/mathematical intelligence acts as a predictor of IELTS reading scores. Razmjoo (2008), on the other hand, found no relationship between MI and language proficiency, While Hashemi (2008) reported a significant positive relationship between verbal intelligence and reading comprehension ability. The findings are, however, in agreement with that of Pishghadam et al. (2010) who reported significant enhancement in students' performance, after receiving visual intelligence-based instruction. Hence, one may conclude that students with higher visual intelligence would perform better, while decoding meaning due to their ability in providing mental images that would facilitate recall of the items, especially when it comes to long reading passages.

Superiority of the visually smart readers to others might also be justified due to their ability in applying reading strategies. As they are stronger with regard to the sense of sight, the speed with which they go through the material would be higher than that of the others. Moreover, they may have a vaster potential to make use of skimming and scanning reading strategies. Furthermore, visualizers are able to form mental images out of the reading passages they are exposed to which may increase retention. Based on Gardner (1983), visual intelligence deals with the ability to perceive the visual world to perform transformations in the actual world. According to Tomlinson (1997), readers who visualize are greater in comprehension than the nonvisualizers.

Based on Ghazanfafi (2009), also, the readers who were instructed to visualize while reading were better readers than those who received no instruction, which emphasizes the role of visualization as a significant factor with regard the reading comprehension.

\section{CONCLUSION}

The results of the present investigation revealed no significant relationship between the two psychological constructs, namely MI and LOC. A significant positive relationship was observed between LOC and reading proficiency. In other words, students who were more internally oriented outperformed those with external orientations. Among the nine intelligence profiles, none but the visual intelligence made the greatest contribution to students' reading proficiency.

Although a number of researches conducted on MIT emphasize the effectiveness of MI application (Campbell \& Campbell, 1999; Hoerr, 2000; Tahriri \& Yamini, 2010), many instructors consider intelligence as a whole factor which is not separable. Students are still decided upon based on a single IQ test regardless of the individual variations that may exist among them. However, classifying the students based on their dominant intelligence preferences, and instructing them according to such a categorization leads to better results definitely.

IDs in terms of LOC are also ignored. As it is observed repeatedly in a number of studies (Findley \& Cooper, 1983; Ghonsooly \& Elahi, 2010; Culvar \& Morgan, 1977) internalizers are better academic achievers compared to externalizers. On the other hand, LOC is believed to predict students' scores and successfulness. Classifying the students based on their LOC orientation and applying various strategies to help students move toward the internal end of the continuum may improve their achievement.

The results of the present investigation are most useful for EFL teachers and instructors. They'd better be aware of the psychological variations and do their best to make use of them. LOC is a dynamic character that may change over time. Based on Cairn et al. (1990), LOC becomes more internal as individuals reach a certain age (cited in Moore, 2006). Being aware of such a fact, teachers may be able to create such a class atmosphere where students' success and failure are not referred to any extraneous factor such as luck and fate but their own effort and shortcomings so that awaken and improve students' sense of responsibility over their own actions.

Further research is needed to find out factors that affect students LOC orientation, if any. Moreover, investigation may be done to see whether MI has any relationship with other language components such as listening and speaking. Further studies could investigate the impact of different profiles of intelligence on various text genres.

\section{REFERENCES}

[1] Armstrong, T. (2009). Multiple intelligences in the classroom. ( $3^{\text {rd }}$ ed.). Alexandria, Virginia: Association for Supervision and Curriculum Development.

[2] Cairns, E., McWhirter, L., Duffy, U., \& Barry, R. (1990). The stability of self-concept in late adolescence: Gender and situational effects. Personality and Individual Differences, 11, 937-944.

[3] Campbell, L., \& Campbell, B. (1999). Multiple intelligences and student achievement: Success stories from six schools. Alexandria, VA: Association for Supervision and Curriculum Development. ED 437180. 
[4] Culvar, I. C., \& Morgan, R. F. (1977). The relationship of locus of control to reading achievement. Paper presented at the Annual Meeting of the International Reading Association, Miami Beach, Florida. Retrieved from http://www.iceis.org/iceis (accessed 24/1/2011)

[5] Dörney, Z. (2005). The psychology of the language learner: Individual differences in second language acquisition. Mahwah, N.J.: Lawrence Erlbaum.

[6] Duttweiler, P. C. (1984). The Internal Control Index: A newly developed measure of locus of control. Educational and Psychological Measurement, 44, 209-221.

[7] Fatemi, A. H., \& Elahi, M. (2010). On the alleged relationship between LOC, L2 reading achievement and use of language learning strategies. Ferdowsi Review, 1(1), 21-47.

[8] Findley, M. J., \& Cooper, H. M. (1983). Locus of control and academic achievement: A literature review. Journal of Personality and Social Psychology, 44, 419-427.

[9] Gardner, H. (1983). Frames of mind: The theory of multiple intelligences. New York: Basic Books.

[10] Gardner, H. (1993). Multiple intelligences: The theory in practice. New York: Basic Books.

[11] Gardner, H. (1999a). Intelligence reframed. Multiple intelligences for the $21^{\text {st }}$ century. New York: Basic Books.

[12] Gardner, H. (1999b). Who owns Intelligence? The Atlantic Monthly, 283(2), 67-76.

[13] Ghazanfari, M. (2009). The role of visualization in EFL learners' reading comprehension and recall of short stories. Iranian Journal of Applied Language Studies, 1 (1), 1-23.

[14] Ghonsooly, B., \& Elahi, M. (2010). Validating locus of control questionnaire and examining its relation to general English achievement. Journal of Teaching Language Skills, 2(1), 117-143.

[15] Goyal, G. (2000). The relationship between locus of control and academic achievement and the role of gender (Master's thesis). Rowan University.

[16] Hashemi, A. (2008). The relationship between multiple intelligences and reading comprehension. Andishah va Raftar. 6(2). $100-110$.

[17] Hoerr, T. R. (2000). Becoming a multiple intelligences school. Alexandria, Virginia: Association for Supervision and Curriculum Development.

[18] Janssen, T., \& Carton, J. S. (1999). The effects of locus of control and task difficulty on procrastination. Journal of Genetic Psychology, 160, 436-442.

[19] Lynch, S., Hurford, D. P., \& Cole, A. (2002). Parental enabling attitudes and locus of control of at-risk and honors students. Adolesence, 37, 527-550.

[20] Matricardi, L. R. (2006). Locus of control and risk behavior among college students (Master's thesis). Rowan University.

[21] McMahon, S. D., Rose, D. S., \& Parks, M. (2004). Multiple intelligences and reading achievement: An examination of the Teele Inventory of multiple intelligences. The Journal of Experimental Education, 73(1), 41-52.

[22] Moore, M. M. (2006). Variations in text anxiety and locus of control orientation in achieving and underachieving gifted and nongifted middle school students(Doctoral dissertation).University of Connecticut.

[23] Motalebzadeh, KH., \& Manouchehri, M. (2009). On the relationship between multiple intelligences and international English language testing system (IELTS) reading scores of Iranian learners. The Quarterly Journal off Fundamentals of Mental Health, $11(2), 135-140$.

[24] Philips, D. (2006). Longman preparation course for TOEFL test: Next generation iBT. United States of America: Pearson Education, Inc.

[25] Pishghadam, R., Khodadady, E., \& Khoshsabk, N. (2010). The impact of visual and verbal Intelligences-based teaching on the vocabulary retention and writen production of Irani Intermediate EFL learners. MJAL. 2(5). 379-395.

[26] Razmjoo, S. A. (2008). On the reationship between multiple inteligences and language proficiency, The Reading Matrix. 8(2). 155-174.

[27] Rotter, J. B. (1966). Internal- External locus of control scale (I.E.). Assess locus of control dimension of personality: Internal or external. Psychological Monographs, 80, 1-28.

[28] Tahriri, A., \& Yamini, M. (2010). On teaching to diversity: Investigatinng the effectiveness of MI. inspiring instructionin an EFL context. The Journal of Teaching Language Skills(JTLS). 2 (1). 165-183.

[29] Tomlinson, B. (1997). The role of visualization in the reading of literature by learners of a foreign language (Unpublished $\mathrm{PhD}$ thesis). University of Nottingham, British Thesis Service.

Farrokhlagha Heidari was born in Zahedan, Iran. She received her PhD in Teaching English as a Foreign Language from Allameh Tabataba'i University, Tehran, Iran. Dr. Heidari is currently an assistant professor in University of Sistan and Baluchestan, Zahedan, Iran.

Najme Khorasaniha was born in Shiraz, Iran in 1987. She received her BA in English Literature from Shiraz University, Shiraz, Iran in 2009. She is currently an MA student in TEFL at University of Sistan and Baluchestan, Zahedan, Iran. Mrs Khorasaniha is an English teacher at Bahar Institute, Iran. 